\title{
Preface to special issue on hybrid and hydrogen technologies for railway operations
}

\author{
Maksym Spiryagin $^{1} \cdot \operatorname{Roger}$ Dixon $^{2} \cdot$ Kevin Oldknow $^{3} \cdot$ Colin Cole $^{1}$
}

Published online: 9 September 2021

(C) The Author(s) 2021

These are exciting times for those working to develop and introduce zero emission technologies for the manufacture and operation of clean transport systems. The automotive industry in particular is taking rapid and significant steps to develop and implement clean and sustainable transport technologies. The railway industry is, relatively speaking, conservative in its progress in this field because it requires expensive long-term financial investment in rolling stock and railway infrastructure. However, the rail industry is also beginning to increase the pace of development. With the transition to clean technologies in rail broadly expected to be implemented in 2030-2050, much of the research now in progress is focused on the appraisal of batteryelectric, hydrogen, and hybrid technologies. This includes modelling, simulation, design, and the development of prototypes for testing on existing railway routes.

Maksym Spiryagin

m.spiryagin@cqu.edu.au

Roger Dixon

R.Dixon@bham.ac.uk

Kevin Oldknow

koldknow@sfu.ca

Colin Cole

c.cole@cqu.edu.au

1 Centre for Railway Engineering, Central Queensland University, Rockhampton, QLD, Australia

2 Birmingham Center for Railway Research and Education, School of Engineering, University of Birmingham, Edgbaston, Birmingham B15 2TT, UK

3 School of Sustainable Energy Engineering, Simon Fraser University, Surrey, BC, Canada
In this special issue, research teams from Australia, Canada, China, Italy, USA, and the UK contribute their reviews, design ideas and concepts in this field. They also outline the progress of several recent and current numerical, experimental, and field works on the development of hybrid and hydrogen solutions applicable to railway applications.

The editors of this special issue believe that the manuscripts published will provide thought provoking and interesting reading, covering their analysis of the development of new ideas in the field of hybrid and hydrogen technologies for rail; we also anticipate that it will stimulate further research in the area, with huge opportunities to make further improvements in alternative power technologies, rolling stock design, and railway infrastructure.

Open Access This article is licensed under a Creative Commons Attribution 4.0 International License, which permits use, sharing, adaptation, distribution and reproduction in any medium or format, as long as you give appropriate credit to the original author(s) and the source, provide a link to the Creative Commons licence, and indicate if changes were made. The images or other third party material in this article are included in the article's Creative Commons licence, unless indicated otherwise in a credit line to the material. If material is not included in the article's Creative Commons licence and your intended use is not permitted by statutory regulation or exceeds the permitted use, you will need to obtain permission directly from the copyright holder. To view a copy of this licence, visit http://creativecommons. org/licenses/by/4.0/. 